\title{
CMAP TOOLS: UM SUPORTE PARA O PROFESSOR ${ }^{1}$
}

\author{
Jaqueline de Jesus Bezerra ${ }^{2}$ \\ Maria Nazareth de Lima Arrais ${ }^{3}$
}

\begin{abstract}
RESUMO. O Cmap Tools é um aplicativo através do qual se constroem mapas conceituais. Um mapa conceitual é uma espécie de esquema gráfico em que palavras e expressões se relacionam significativamente. Este $\operatorname{artigo}^{4}$ busca, pois, apresentar o mapa conceitual, o Cmap Tools e suas funções, como também as possibilidades de trabalho com esse aplicativo para o ensino. A presente pesquisa é bibliográfica e de caráter qualitativo. $\mathrm{O}$ aparato teórico está pautado, principalmente, no que respeita à teoria dos mapas conceituais, nas contribuições de Costa, Brennand e Albuquerque (2011), Marriott e Torres (2014) e Novak e Cañas (2010). A pesquisa aponta o Cmap Tools como uma estratégia de ensino pautada na tecnologia e na inovação.
\end{abstract}

Palavras-chave: mapa conceitual; Cmap Tools; ensino.

\section{CMAP TOOLS: A SUPPORT FOR THE TEACHER}

\begin{abstract}
This article seeks to present the conceptual map, Cmap Tools and its functions, as well as the possibilities of working with this application for teaching. The present research is bibliographical and from the qualitative type. The theoretical apparatus is based mainly on the contributions of Costa, Brennand and Albuquerque (2011), Marriott and Torres (2014) and Novak and Cañas (2010). The search points to Cmap Tools as a teaching strategy based on technology and innovation.
\end{abstract}

Keywords: conceptual map; Cmap Tools; teaching.

\section{CMAP TOOLS: UN SOPORTE PARA EL PROFESOR}

RESUMEN. Este artículo busca presentar el mapa conceptual, el Cmap Tools y sus funciones, así como las posibilidades de trabajo con esa aplicación para la enseñanza. La presente investigación es bibliográfica y de carácter cualitativo. El aparato teórico está pautado, principalmente, en las contribuciones de Costa, Brennand y Albuquerque

\footnotetext{
${ }^{1}$ Este trabalho é um recorte da dissertação de Mestrado, defendida em 21 de fevereiro de 2018, na Universidade Federal de Campina Grande (UFCG).

${ }^{2}$ Mestra em Letras pela Universidade Federal de Campina Grande (UFCG), Campus Cajazeiras-PB e Doutoranda em Letras pela Universidade do Estado do Rio Grande do Norte (UERN).

${ }^{3}$ Professora adjunta da Universidade Federal de Campina Grande (UFCG), Unidade Acadêmica de Letras
} 
(2011), Marriott y Torres (2014) y Novak y Cañas (2010). La investigación apunta el Cmap Tools como una estrategia de enseñanza pautada en la tecnología y la innovación.

Palabras clave: mapa conceptual; Cmap Tools; enseñanza.

\section{Introdução}

Buscar novas estratégias de ensino é uma necessidade do docente no contexto atual de educação. $\mathrm{O}$ uso do mapa conceitual em sala de aula pode ser uma boa estratégia para o ensino e a aprendizagem. O Cmap Tools é um programa que possibilita a produção de mapas conceituais por meio de um menu diversificado.

Nesse sentido, o objetivo geral deste trabalho é apresentar o software Cmap Tools e suas principais funções. Pretende-se ainda, especificamente, definir mapa conceitual e apontá-lo como um suporte para o professor no processo de ensino e aprendizagem em sala de aula.

Para tanto, realizamos uma pesquisa bibliográfica, fundamentada em pesquisas já realizadas e publicadas. Sua natureza é aplicada, considerando-se que os conhecimentos produzidos a partir deste trabalho podem ser aplicados à prática do professor. A abordagem aqui adotada é qualitativa, pois o intuito é a compreensão e a interpretação da proposta.

Este artigo se justifica, então, por apresentar uma proposta inovadora, pois como fomos atraídos por ela a partir de práticas com resultados exitosos, imaginamos que possamos atrair outros a buscarem semelhantes ou mais produtivas práticas com resultados exitosos para a sala de aula.

O artigo está estruturado em três partes centrais: inicialmente trazemos informações sobre o mapa conceitual, depois apresentamos o Cmap Tools como um software para construir mapas conceituais; em seguida, damos ênfase às funções mais relevantes e as vantagens de utilização desse recurso em sala de aula. 


\section{O mapa conceitual}

O mapa conceitual foi criado pelo americano Joseph Donald Novak o qual afirma, juntamente com Cañas (2010, p. 10), que "mapas conceituais são ferramentas gráficas para a organização e representação do conhecimento". Destacamos também a definição de Moreira e Buchweitz (1987, p.11) os quais afirmam que mapas conceituais "são diagramas hierárquicos indicando os conceitos e as relações entre esses conceitos”.

Vale ressaltar que o mapa conceitual se baseia na Teoria da Aprendizagem Significativa de Ausubel. De acordo com Moreira (2010, p. 17), "essa estratégia revelou ter um alto potencial para facilitar a negociação, construção e aquisição de significados. " Logo, vê-se que usar mapas conceituais em sala de aula é uma boa estratégia para que os alunos aprendam significativamente.

Em qualquer disciplina, por meio de sequências didáticas, em cursos, seminário ou em outras situações de aprendizagem, os mapas conceituais podem ser utilizados. De um mesmo conteúdo, podem nascer diferentes mapas de conceitos que são construídos de acordo com a compreensão do produtor, que pode ser tanto o professor quanto o aluno.

Conhecer os passos da construção desse tipo de diagrama é necessário para que se tenham estruturas bem produzidas e que demonstrem significativamente o conhecimento. Como ferramenta didático-pedagógica, sem dúvidas, o professor tem um papel extremamente importante em todas as etapas de produção dos mapeamentos de conceitos construídos por seus alunos, devendo assumir tanto uma postura construtivista como também interacionista, interagindo com os discentes e possibilitando a interação dos colegas em sala de aula para juntos construírem o conhecimento.

Segundo Moreira (2010), para a construção de um mapa conceitual, primeiramente é preciso listar os principais conceitos do conteúdo a ser mapeado, não devendo ser menos que seis, nem mais que dez. Tais conceitos devem ser ordenados, de modo que o mais geral deve ficar no topo e os outros ligados a ele através de linhas, as quais são rotuladas com palavras-chave que esclareçam a relação entre os conceitos.

Na maioria das vezes, as informações dos mapas são colocadas dentro de figuras geométricas como elipses e retângulos. Normalmente os conceitos gerais ficam dentro de 
elipses, enquanto os específicos ficam em retângulos, entretanto há outros mapas em que não se usam essas figuras.

Algo essencial na criação de mapas conceituais são as palavras ou frases de ligação usadas para relacionar os conceitos. Elas elucidam o tipo de relação entre os conceitos e o seu uso exige uma análise e uma leitura aprofundada do conteúdo mapeado. Tais palavras de ligação são verbos ou locuções verbais, preposições, conjunções e as frases de ligação são orações curtas.

A ligação dos conceitos gerais aos intermediários e específicos através das palavras ou frases de ligação forma as proposições, que são afirmativas formadas por meio da relação estabelecida entre esses conceitos. Se a proposição não é bem formada, a informação pode estar sendo mapeada de forma inadequada e a compreensão do conteúdo do mapa se torna comprometida.

Pode-se construir um mapa conceitual somente usando-se papel e lápis ou caneta, mas esse esquema também pode ser construído no software Cmap Tools, que permite produções mais enriquecidas e dinâmicas por meio dos recursos tecnológicos desse aplicativo.

Para compreendermos como usar o software educacional Cmap Tools, a seção seguinte vai apresentá-lo e também o passo a passo de como construi-lo.

\section{Conhecendo o cmap tools}

O Cmap Tools é um programa que produz mapas conceituais digitais. "É um software free, desenvolvido [...] sob a supervisão do Dr. Alberto J. Cañas, [...] utiliza a tecnologia Java e permite a sua utilização em diversas plataformas. "(COSTA; BRENNAND; ALBUQUERQUE, 2011, p. 214).

De acordo com Novak e Cañas (2010, p. 17), “o software torna fácil para usuários de todas as idades elaborarem e modificarem mapas conceituais da mesma forma que um processador de texto facilita a produção textual. " Esse programa foi desenvolvido pelo Institute for Human and Machine Cognition - IHMC (Instituto para a Cognição Humana e Mecânica), associado à West Florida University (Universidade do Oeste da Flórida). 
O Cmap é uma boa ferramenta para se produzir mapas conceituais com rapidez e praticidade. O professor pode construir os mapas que usará na aula, como também pode mostrar aos alunos como manusear o programa para construírem os mapas deles. Conforme Marriott e Torres (2014, p. 194 -195), o Cmap Tools

[...] oferece download gratuito para fins pedagógicos, podendo ser utilizado livremente por escolas, universidades e entidades sem fins lucrativos. Sua interface é simples e fácil de usar tanto por crianças quanto por adultos nos mais variados domínios do conhecimento em vários países. A cada nova versão do software Cmap Tools mais recursos são criados e disponibilizados tendo por base os estudos de Novak e de pesquisadores comprometidos com os princípios da Aprendizagem Significativa e da construção do conhecimento.

Além de ser um programa prático, Marriott e Torres (2014) afirmam que é fácil manuseá-lo. É simples e gratuito instalá-lo no computador pessoal ou no do trabalho, seja escola, empresa ou outra instituição. O mais importante nesse programa é que ele segue os princípios de Novak e de Ausubel, o que contribui para um maior comprometimento com a aprendizagem significativa.

Para iniciar a construção de um mapa no Cmap Tools, damos um clique duplo na tela em branco, já dentro do aplicativo, então aparece a forma do primeiro conceito a ser mapeado e, acima, aparece, automaticamente, a seta para ligá-lo a outro, através de uma palavra ou frase de ligação:

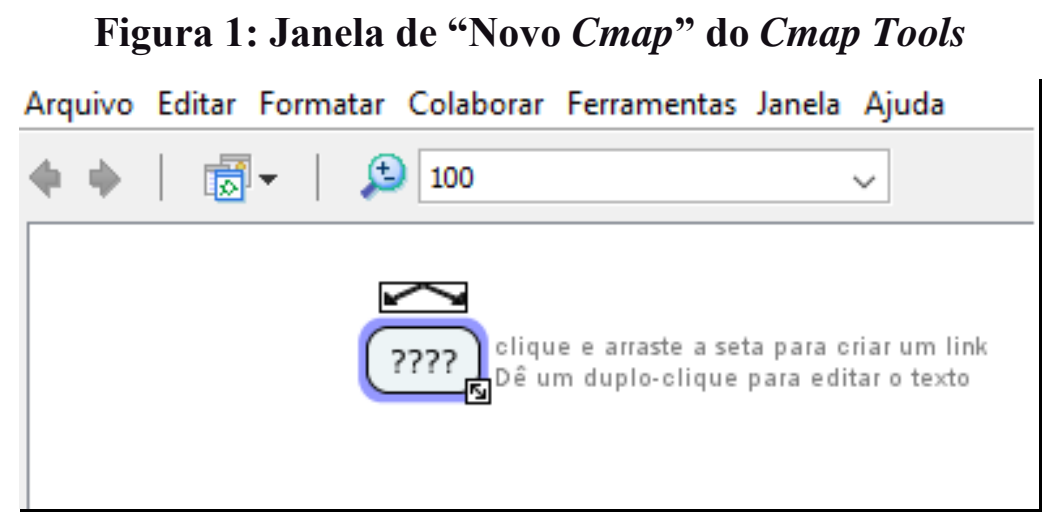

Fonte: https://cmap.ihmc.us (2017)

No menu, temos: “Arquivo", "Editar”, "Formatar", "Colaborar”, "Ferramentas", "Janela" e "Ajuda", opções que vão desde à tarefa de salvar um Cmap, por exemplo, até informações a mais sobre mapas conceituais, ou seja, o aplicativo traz um rico menu para 
o incremento e aprimoramento dos mapeamentos produzidos. Destacaremos aqui algumas funções primordiais para a construção dinâmica de um Cmap e para facilitar algumas operações necessárias no programa. Destacamos inicialmente a opção “Arquivo" (Figura 2) e a opção "Editar” (Figura 3), as quais têm as seguintes funções:

Figura 2: Janela "Arquivo" do Cmap Tools

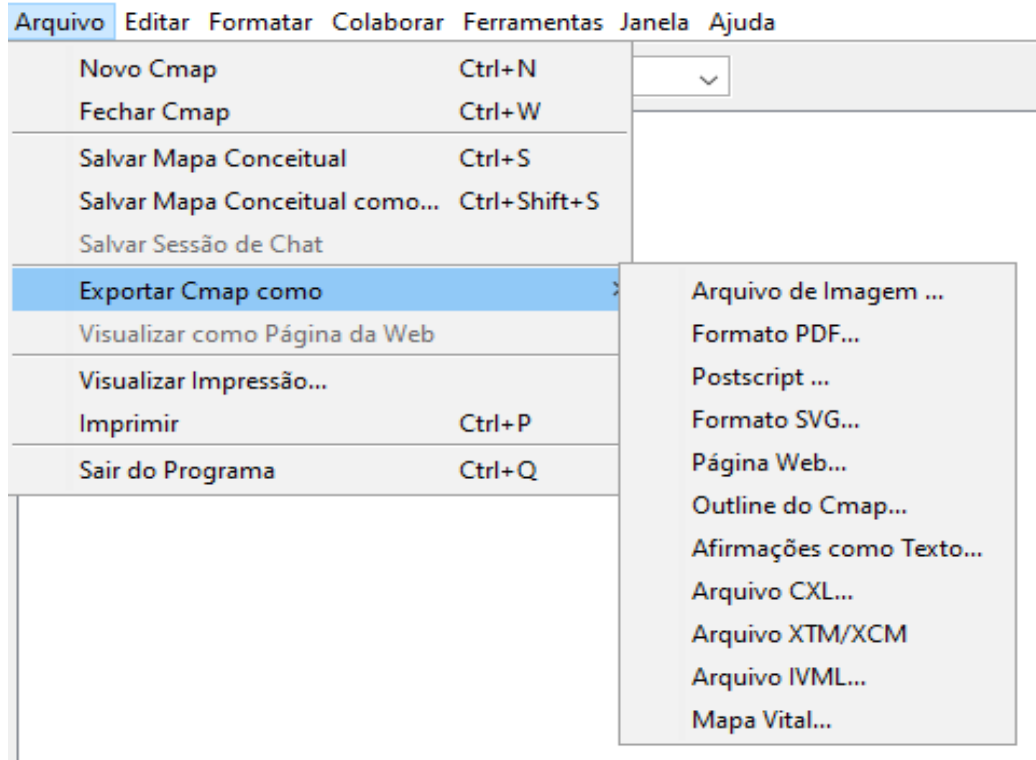

Fonte: https://cmap.ihmc.us (2017)

Figura 3: Janela "Editar" do Cmap Tools

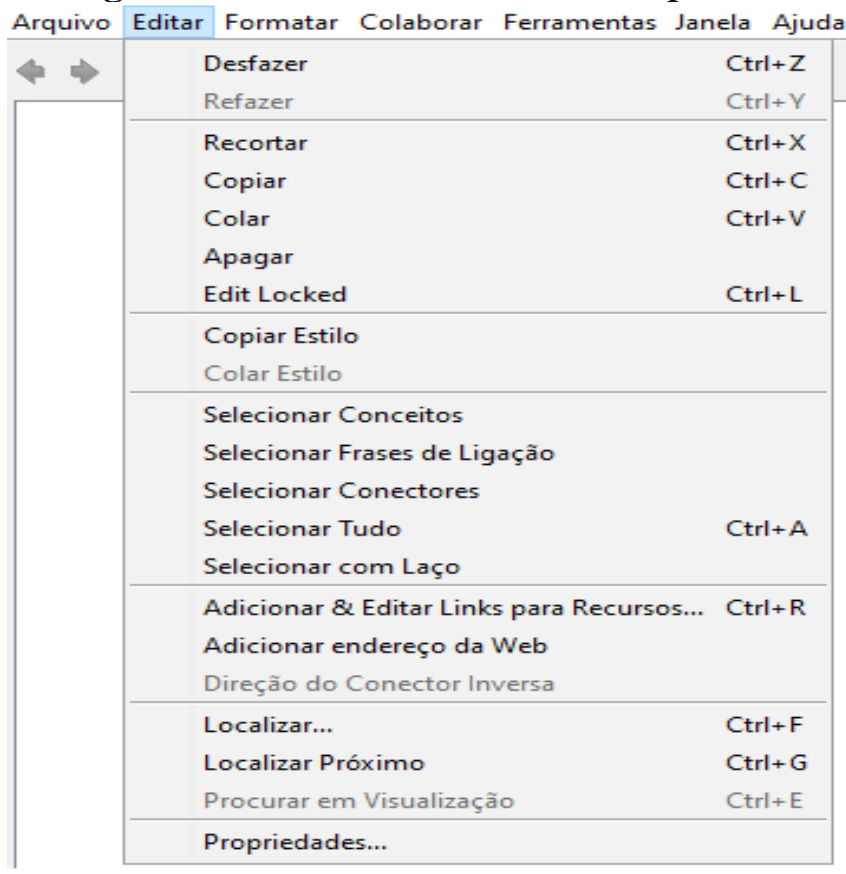

Fonte: https://cmap.ihmc.us (2017)

RPI Revista de Pesquisa Interdisciplinar, Cajazeiras, v. 3, n. 1, 142-158, jan/jul. de 2018. 
A formatação, bem como a personalização, é feita ao clicarmos em "Formatar estilos", opção onde aparecem quatro abas de formatação de estilos: fonte, objeto, linha e Cmap, conforme se vê na Figura 4 abaixo:

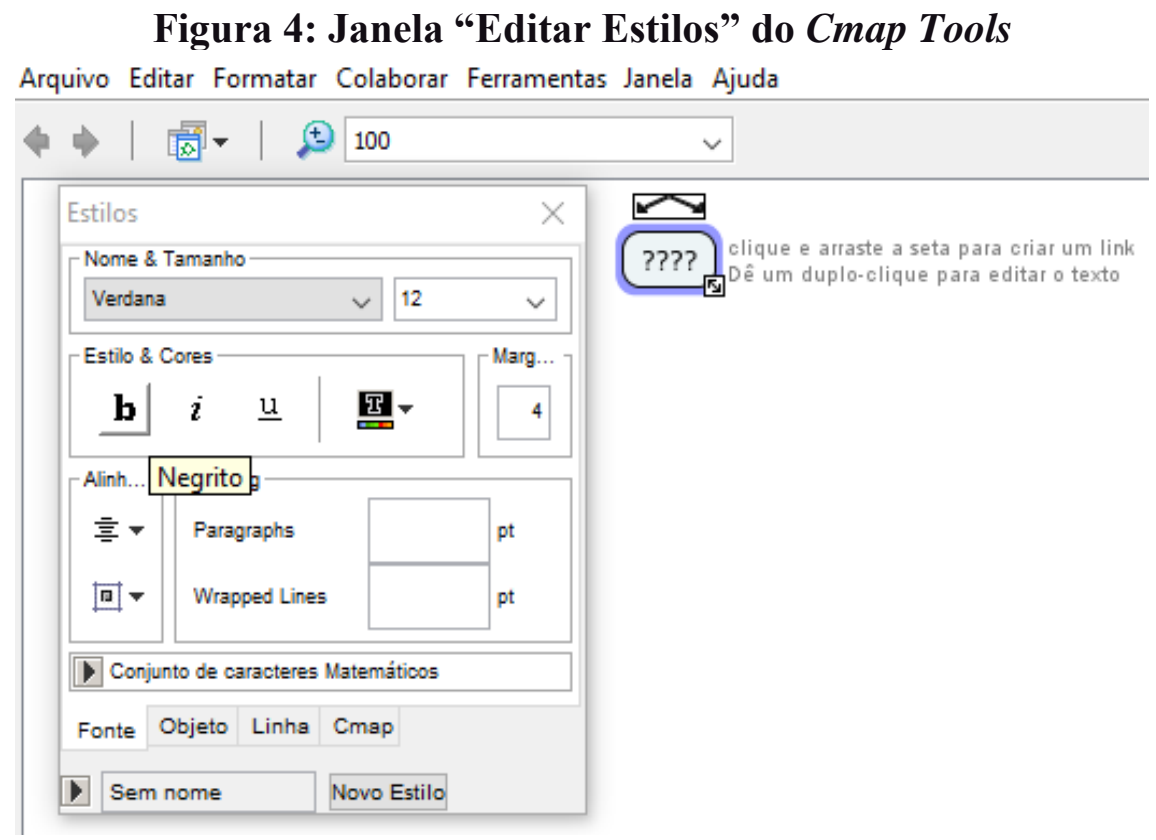

Fonte: https://cmap.ihmc.us (2017)

A Figura 5 ilustra a formatação de fonte, que também destacamos, uma vez que essa função é importante para o aspecto visual do mapeamento digital. O primeiro conceito "Mapas conceituais", está em Arial, no tamanho 14, na cor verde, com alinhamento centralizado e margem 4.

Após a fonte, tem-se a aba de formatação do objeto, onde se pode colocar cor na forma do conceito, sombra nessa mesma forma que pode ser um quadrado, elipse ou círculo e é possível ainda, nessa aba, incluir uma imagem de fundo, alinhar e esticar a forma geométrica escolhida para o conceito. Na figura 6, tem-se um print que ilustra algumas formatações feitas, a saber, a escolha do círculo para o primeiro conceito ao qual foi dada a cor amarelo, com sombra azul. 
Figura 5: Janela "Editar Estilos - Fonte" do Cmap Tools

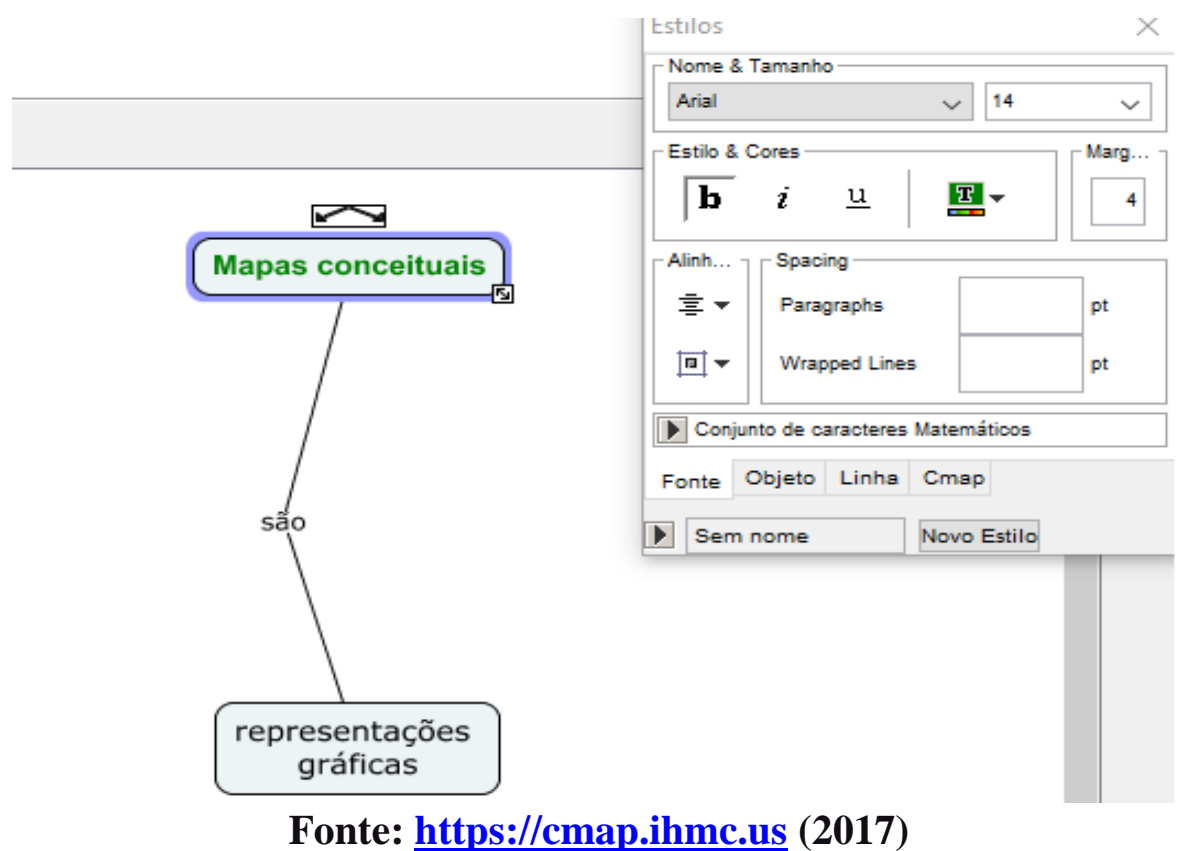

Figura 6: Janela "Editar Estilos - Objeto" do Cmap Tools

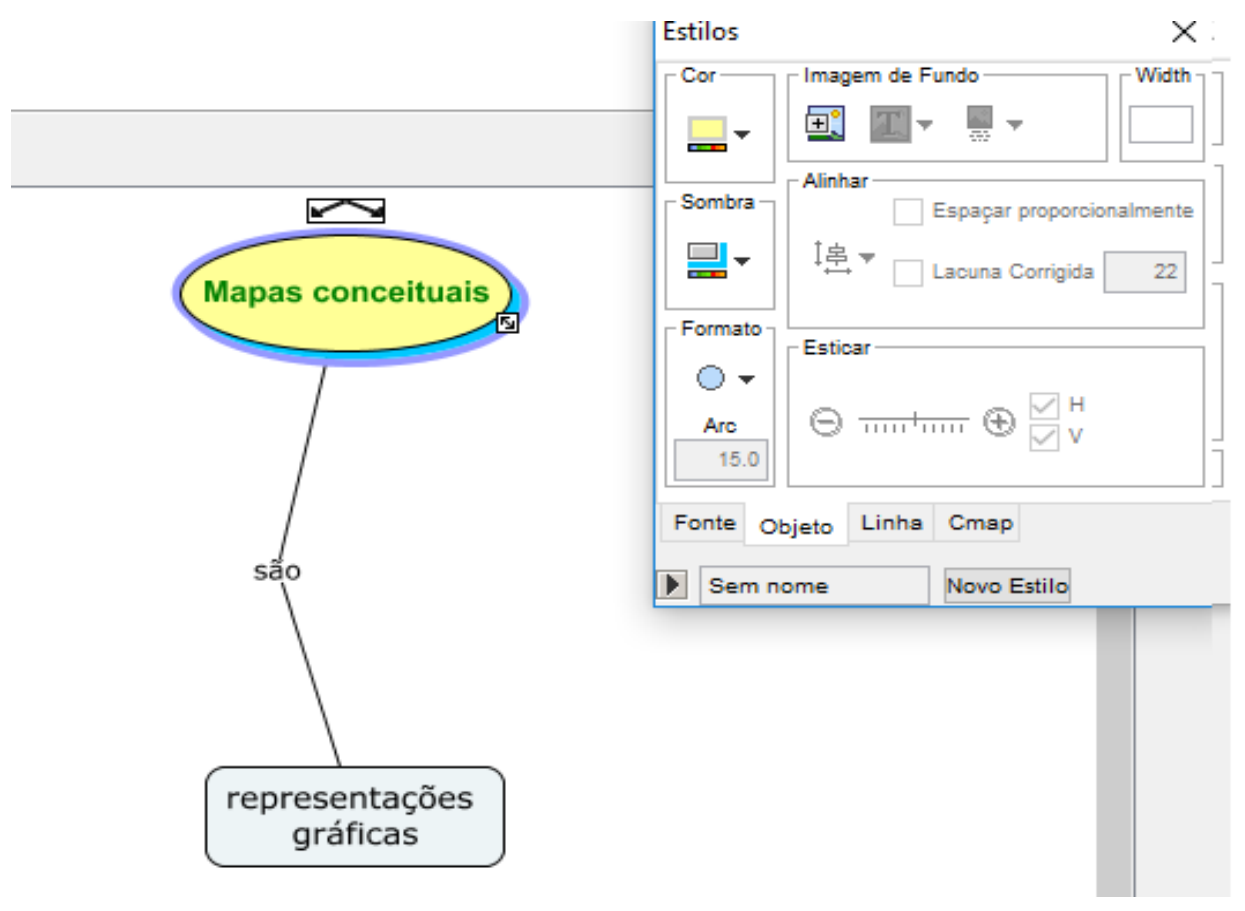

Fonte: https://cmap.ihmc.us (2017)

Na Figura 7 tem-se a formatação das linhas que ligam os conceitos. Vê-se que as setas estão em azul, espessura mais fina, que correspondem ao número 1, enquanto o 
número 6 corresponde à mais grossa e o estilo não é pontilhado. A primeira seta está no formato arco, enquanto a segunda está no formato linha reta, mas também poderia ter uma forma curvada com três ou quatro pontos, ou forma de vetor:

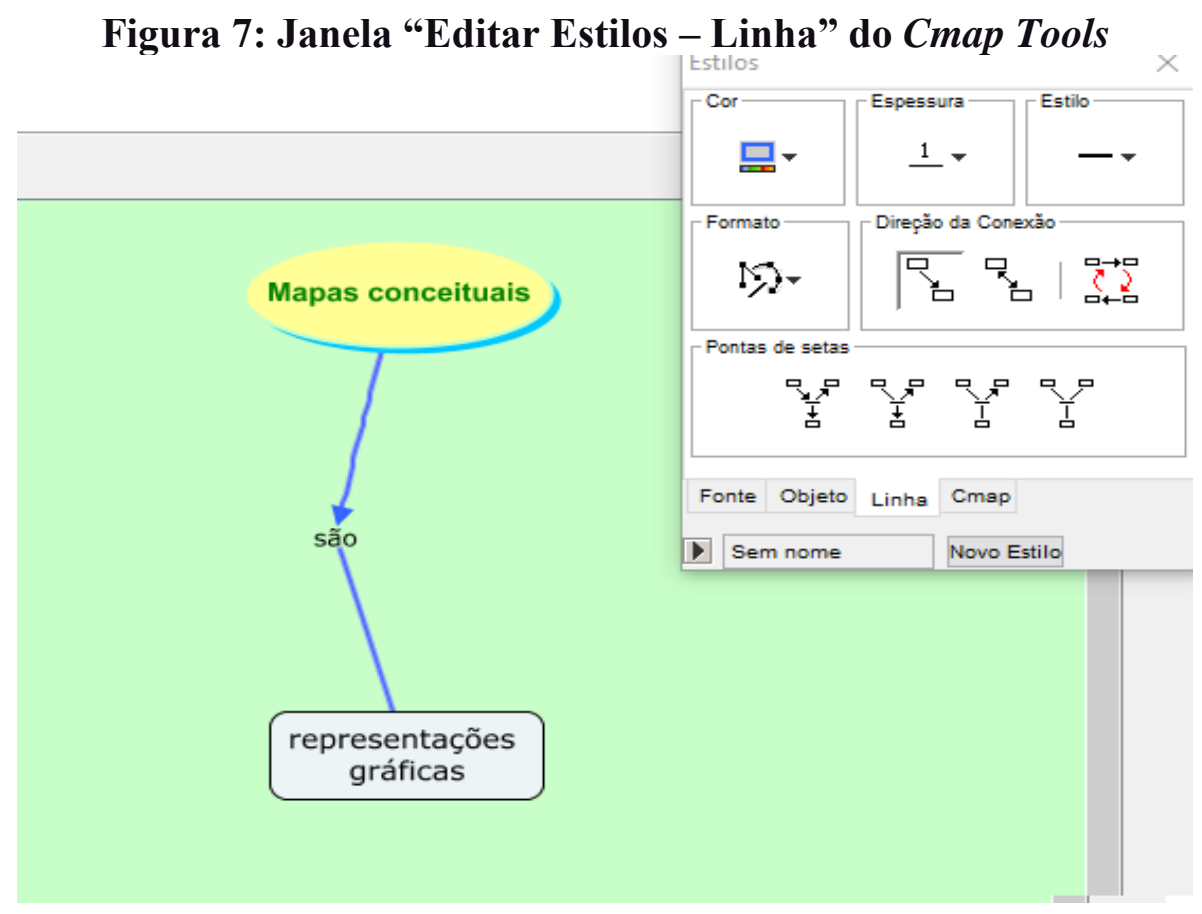

Fonte: https://cmap.ihmc.us (2017)

Na Figura 8, tem-se a aba de formatação do Cmap, que inclui colocar cor e ainda colocar uma imagem ao fundo, o que contribui para um Cmap personalizado e visualmente chamativo, de forma a despertar a atenção de quem verá o mapa conceitual.

Figura 8: Janela "Editar Estilos - Cmap" do Cmap Tools

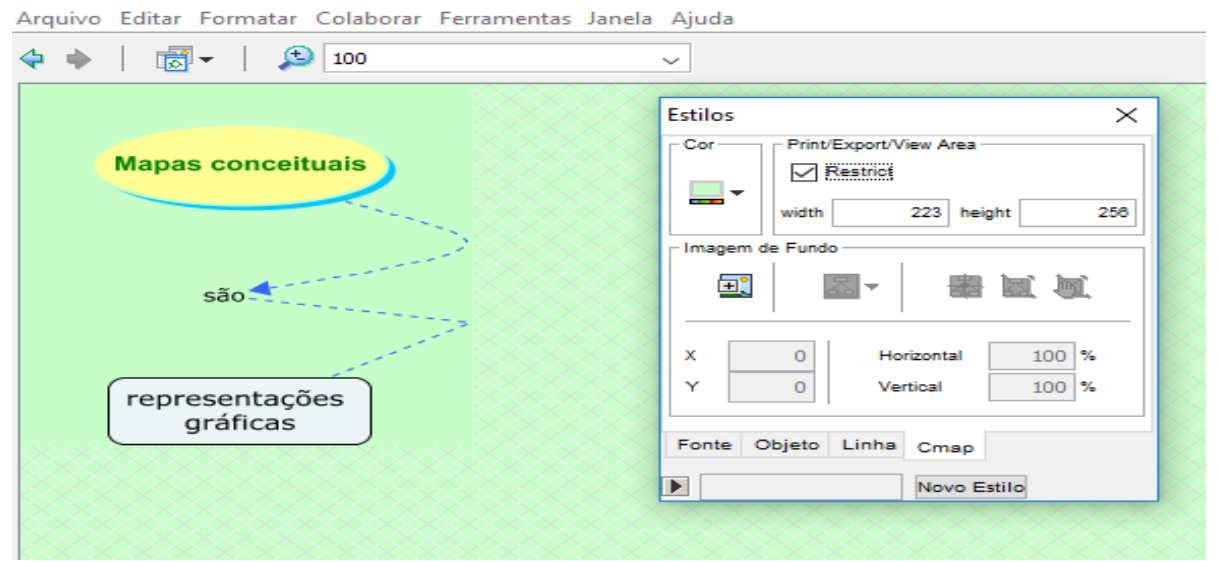

Fonte: https://cmap.ihmc.us (2017) 
Na opção "Colaborar", os produtores podem juntar o Cmap à sopa ${ }^{5}$, opção "na qual eles possam partilhar proposições, mas não vejam os mapas uns dos outros." (NOVAK; CAÑAS, 2010, p. 19). Assim os elaboradores colaboram entre si, construindo proposições mais precisas ao contexto do mapeamento.

Na opção de comentar, abre-se uma janela em que se digitam textos. É um recurso para informações extras referentes ao conteúdo do mapa conceitual. Tal janela pode ser minimizada e, para vermos as informações dela, é só clicar no ícone, o que representa uma boa opção para mapas com muitos conceitos os quais ocupam um grande espaço, consoante exemplo abaixo:

Figura 9: Janela "Comentário" do Cmap Tools

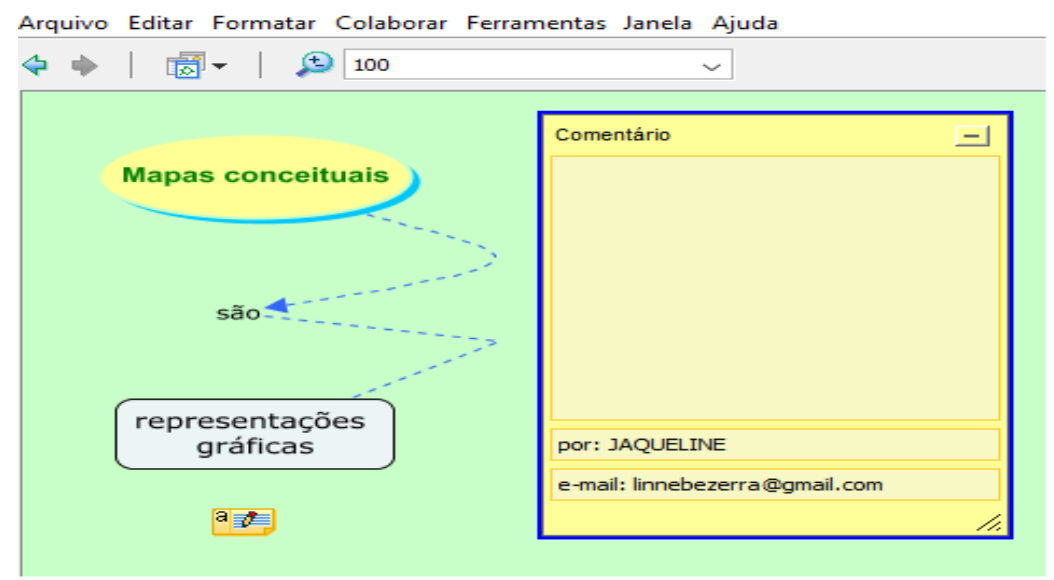

Fonte: https://cmap.ihmc.us (2017)

Além da opção de "comentar", visualizada em detalhes na Figura 9, o usuário do software tem ainda a opção de escolher se quer ou não "mesclar nós". Quando essa opção é selecionada aparece a janela abaixo com a seguinte informação:

\footnotetext{
${ }^{5}$ Sopa é uma espécie de grupo em que se publicam mapas conceituais os quais podem ser vistos por outros participantes da sopa a fim de que se compartilhem proposições dos mapeamentos de conceitos. "Algumas sopas possuem tópicos de discussão anexados questionando ou comentando a proposição. " (NOVAK; CAÑAS, 2010, p. 20).
} 


\section{Figura 10: Janela "Mesclar nós" do Cmap Tools}

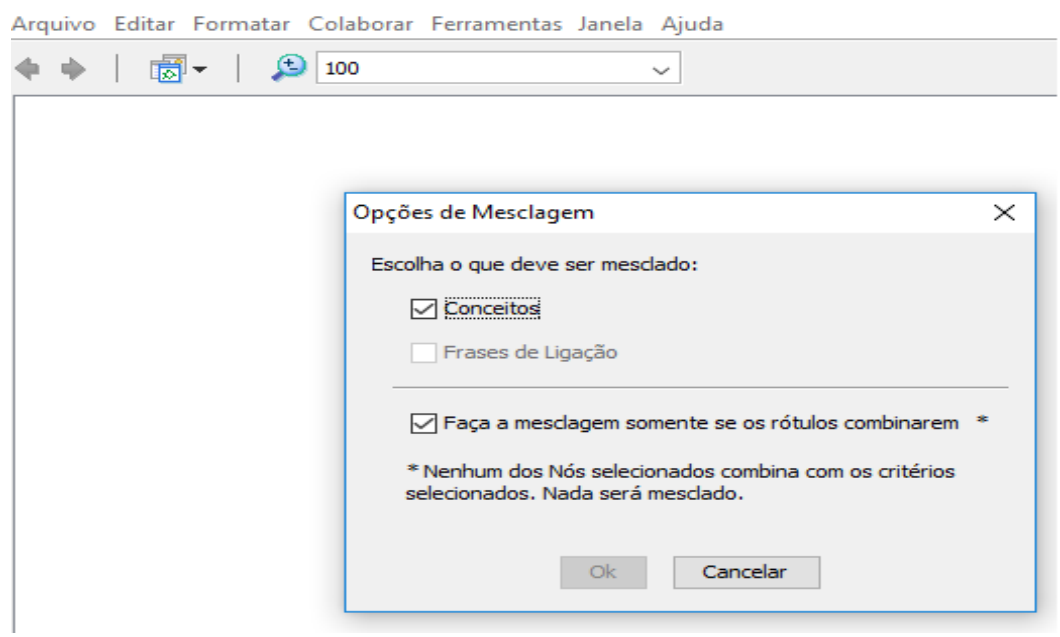

Fonte: https://cmap.ihmc.us (2017)

O produtor deve escolher se quer mesclar conceitos ou palavras de ligação e fazer a "mesclagem apenas se os rótulos combinarem" como mostra a Figura 10. Quando os conceitos ou palavras de ligação selecionados não combinam com os critérios selecionados, nada é mesclado. Após a opção de "mesclar nós”, o produtor pode fazer um "grande nó6", juntando proposições que passam a representar um só conceito ao qual se ligam outros por outras palavras de ligação:

\section{Figura 11: Exemplo de "Grande nó" no Cmap Tools}

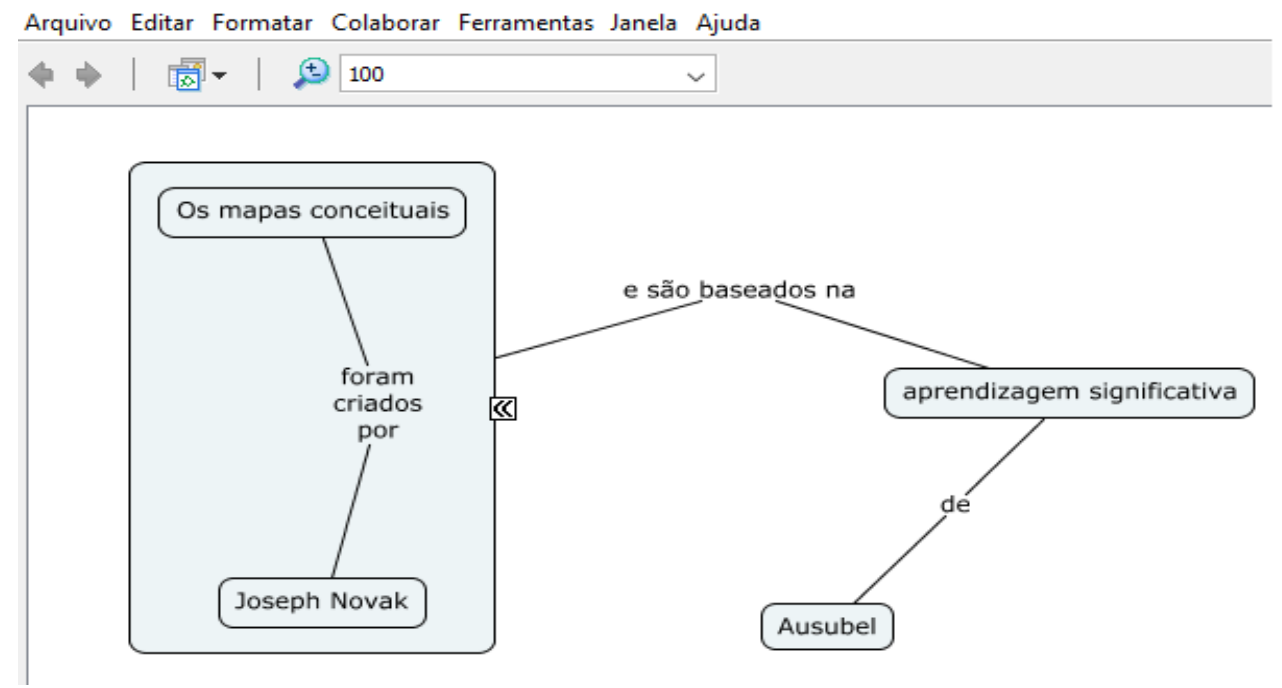

Fonte: https://cmap.ihmc.us (2017)

\footnotetext{
${ }^{6}$ Nó é uma ligação entre proposições que se unem em um só conceito e às quais podem ser ligadas outras proposições.
}

RPI Revista de Pesquisa Interdisciplinar, Cajazeiras, v. 3, n. 1, 142-158, jan/jul. de 2018. 
Observa-se na Figura 11 que a proposição "os mapas conceituais foram criados por Novak" ficou inteira como um conceito dentro de uma forma geométrica e a ela se ligou a proposição “e são baseados na aprendizagem significativa de Ausubel”. Ao clicar nas setas do primeiro quadrado, voltadas para a esquerda, encontramos o outro conceito que foi mesclado no grande nó, "Mapas conceituais são representações gráficas de conceitos". Um ou mais conceitos poderiam ainda ser incluídos ao grande nó, representado pelas setas, que na imagem abaixo estão voltadas para a direita:

Figura 12: Exemplo de "Grande nó" no Cmap Tools

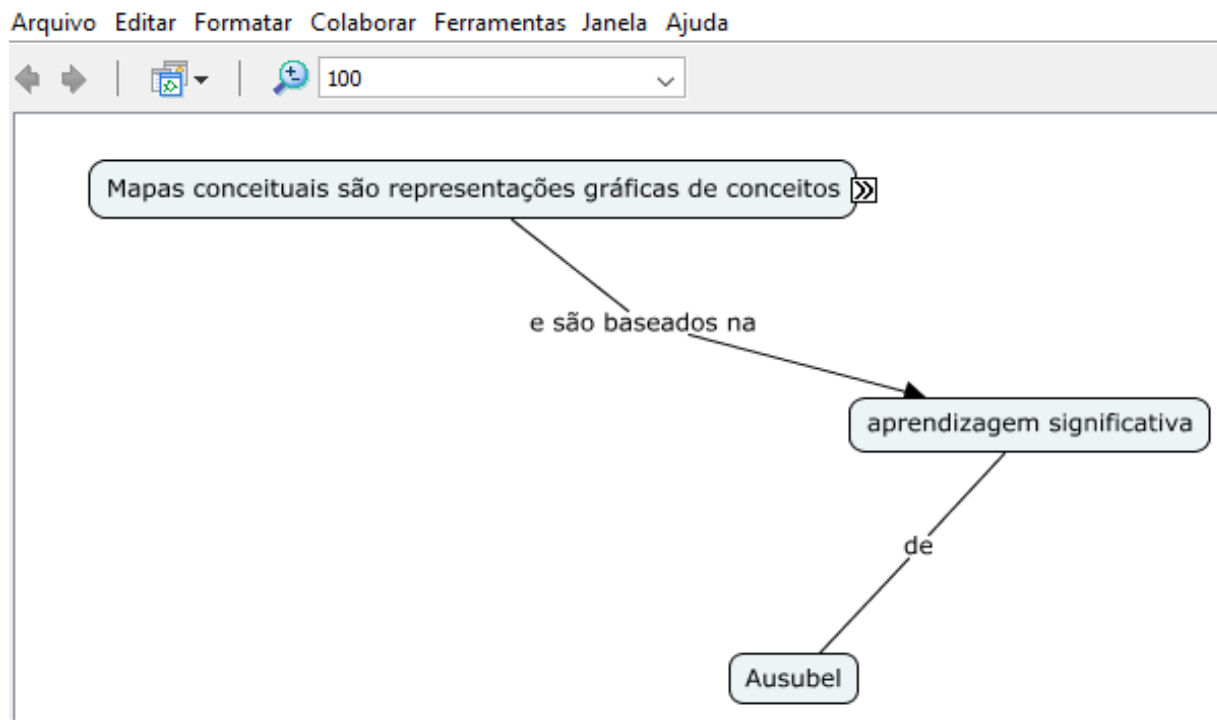

Fonte: https://cmap.ihmc.us (2017)

A Figura 13 mostra a "Busca", que é a penúltima opção da janela "Ferramentas" a qual é também válido destacar. Para buscar alguma informação, é necessário colocar alguma palavra ou frase no campo específico para isso e clicar na opção "Busca", conforme se pode observar na figura abaixo:

RPI Revista de Pesquisa Interdisciplinar, Cajazeiras, v. 3, n. 1, 142-158, jan/jul. de 2018. 
Figura 13: Janela "Busca" do Cmap Tools

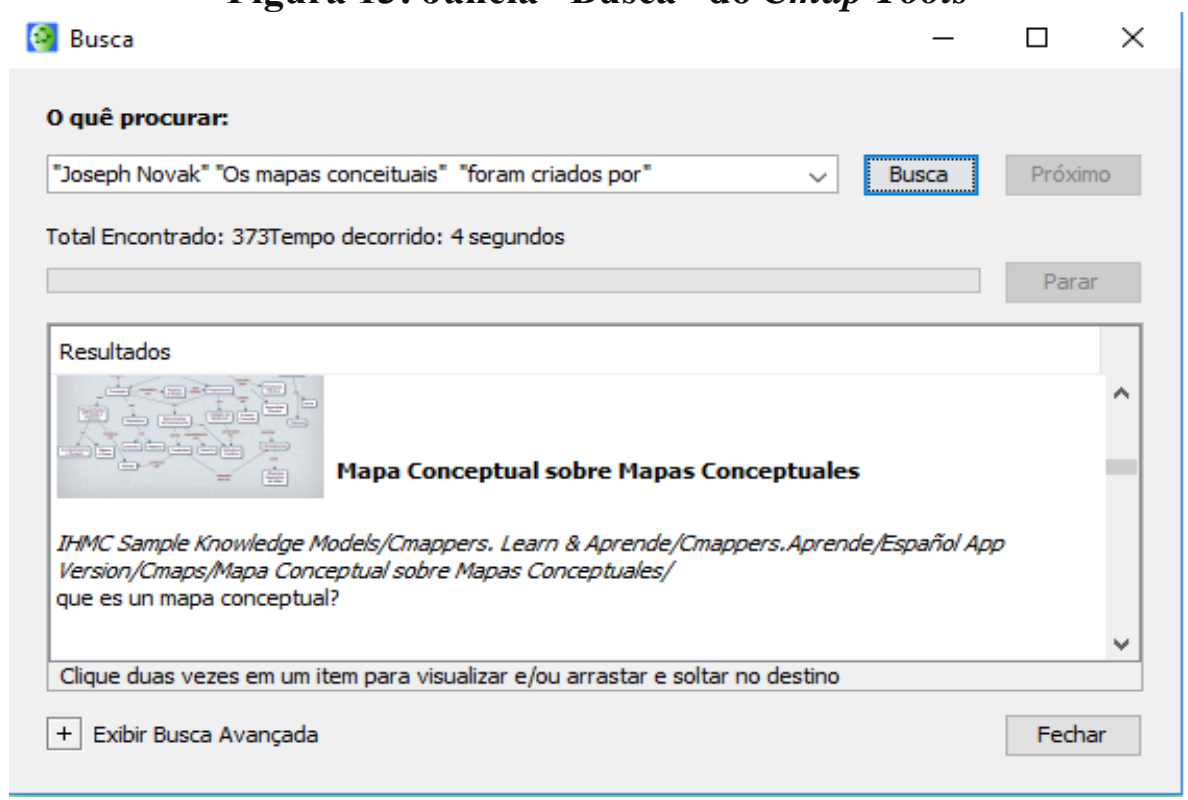

Fonte: https://cmap.ihmc.us (2017)

Como exemplo de busca, colocamos a proposição "Os mapas conceituais foram criados por Joseph Novak" e em apenas 04 segundos foram encontrados 373 links relacionados à busca realizada sobre a informação solicitada. Ao clicarmos num link se abre o mapa conceitual. Para demonstrar a pesquisa da proposição mencionada, clicamos no link de um mapa conceitual exatamente sobre "Mapas Conceptuales", que pode ser visto na Figura 14:

Figura 14: Exemplo de busca no Cmap Tools

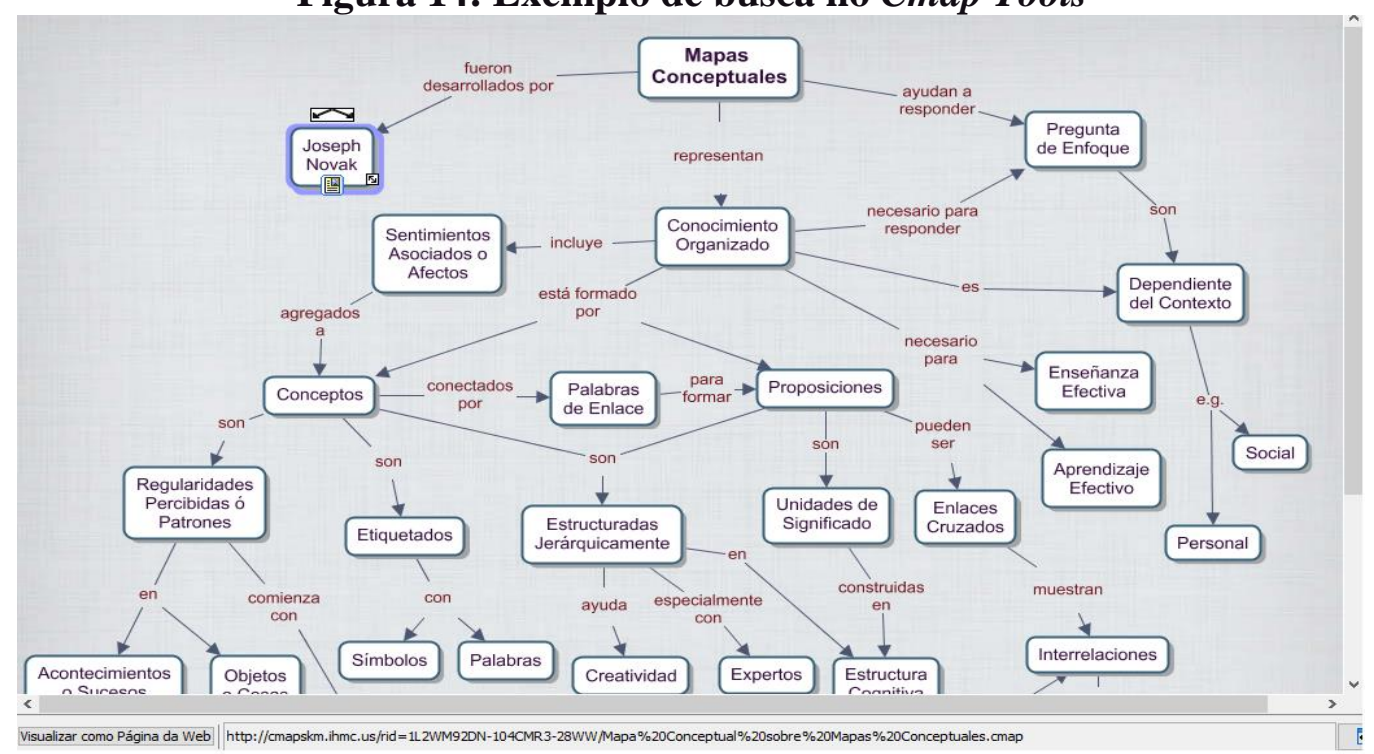

Fonte: https://cmap.ihmc.us (2017)

RPI Revista de Pesquisa Interdisciplinar, Cajazeiras, v. 3, n. 1, 142-158, jan/jul. de 2018. 
Por fim, há o menu “Ajuda", do qual a primeira função é “ajuda do Cmap”, página em que se pode aprender a criar um Cmap, adicionar um conceito, criar proposições, salvar e abrir um Cmap, criar uma pasta, trabalhar com recursos, imprimir um Cmap, entre outras inúmeras tarefas:

Figura 15: Janela "Ajuda do Cmap" do Cmap Tools

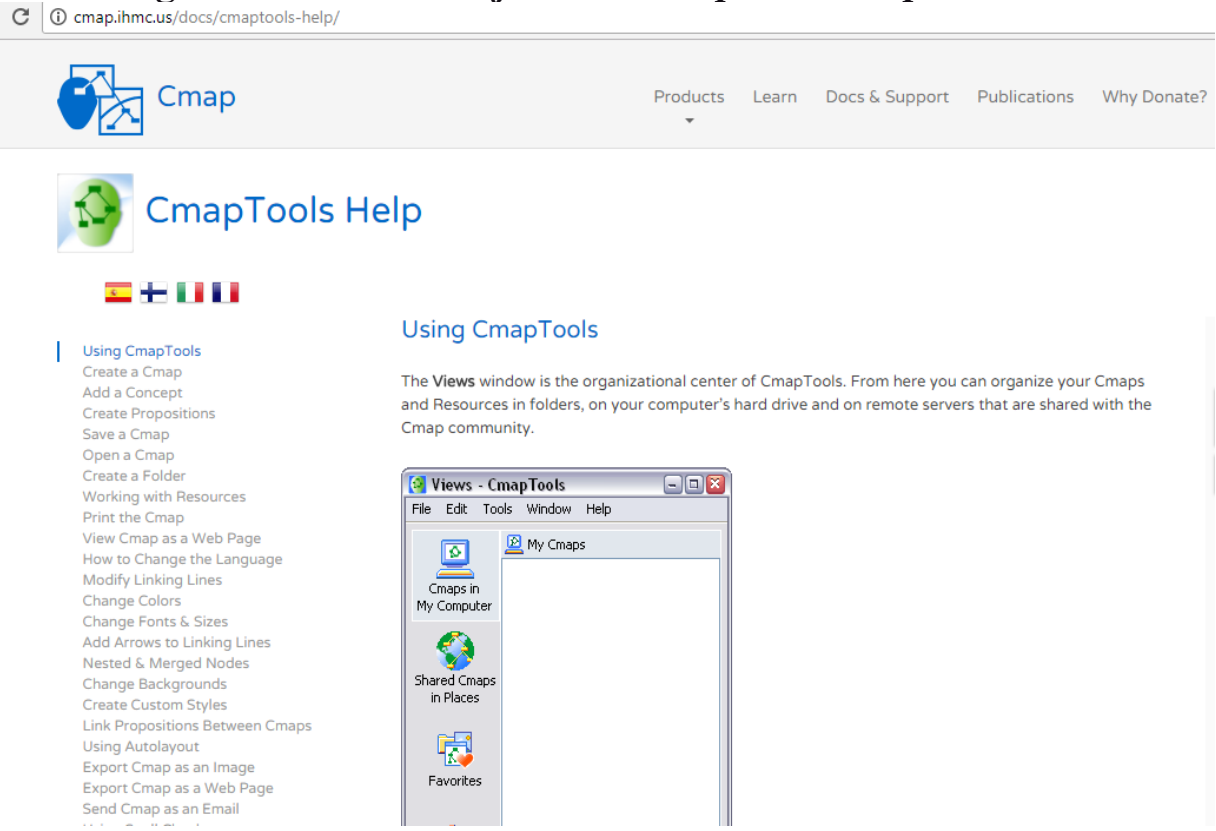

Fonte: https://cmap.ihmc.us (2017)

Agora que já sabemos manusear o Cmap Tools, vamos discutir um pouco sobre as vantagens dessa ferramenta na sala de aula.

\section{Vantagens do uso do cmap tools em sala de aula}

Além de ser um recurso tecnológico, o Cmap Tools é um recurso didático inovador que facilita a aprendizagem dos alunos. Isso se deve à dinamicidade do aplicativo que possibilita um aspecto visual chamativo prendendo a atenção de quem o observa. Em Bezerra (2017, p. 125) encontramos a seguinte afirmação a respeito da apresentação de um conteúdo por meio de um mapa conceitual: 
A listagem dos conceitos em um esquema visual, sem dúvidas, pode facilitar a retenção do assunto pelo aluno de um modo mais prático do que simplesmente uma exposição oral sem nenhum recurso, ou do que a leitura longa de um texto sobre aquele conteúdo, por exemplo.

Logo, expor algum conteúdo usando-se esse recurso pode tornar mais fácil a assimilação das informações do que apenas ouvir falar de um assunto ou só ler sobre um assunto, de forma que os mapas conceituais, especialmente feitos pelo Cmap Tools, podem acompanhar uma aula expositiva ou uma leitura.

As funções que o aplicativo apresenta contribuem para a construção de mapeamentos ricos de conteúdo, por exemplo, a opção "comentário" permite a ampliação de informações relacionadas ao assunto mapeado, como a menção a conhecimentos interdisciplinares, a fatos históricos, geográficos ou de outra natureza ligados ao tema daquele mapeamento.

A opção do "grande nó" relaciona conceitos, os quais se relacionam a outros, mais específicos. Essa função contribui para mostrar a ligação de assuntos que apresentam uma relação ou são dependentes entre si, em um mesmo mapeamento, de um modo mais dinâmico, que facilite para o aluno a percepção dessas relações ou dependências entre conteúdos.

O professor, utilizando um Cmap para explanar um conteúdo, pode clicar na opção "busca" e pesquisar outros mapeamentos sobre o mesmo tema que está sendo apresentado, o que amplia mais ainda o conhecimento repassado, permite que os alunos compreendam melhor aquele assunto e vejam as várias possibilidades de mapeamento de um mesmo conteúdo.

Por fim, é válido ressaltar que o docente pode utilizar o Cmap Tools para trabalhar conteúdos em suas aulas com estratégia diretiva de ensino explícito e ativo, entretanto é importante que incentive o uso do aplicativo pelos alunos, para que estes possam também produzir mapeamentos no programa. Para explicar aos discentes o que devem saber sobre como criar mapas conceituais usando a ferramenta, o professor pode utilizar o menu “Ajuda”, onde estão todas as informações necessárias relacionadas à produção de Cmaps. 


\section{Considerações finais}

É fato que o software Cmap Tools é riquíssimo, visto que oferece inúmeras possibilidades de personalizações, edições, interações entre os usuários do aplicativo, ampliação e busca de informações. Além disso, permite a quem está construindo um mapa conceitual por esta ferramenta criatividade e apreensão de conceitos.

Das discussões, inicialmente, pudemos apreender definições de mapas conceituais, os quais são derivados dos princípios da Teoria da Aprendizagem Significativa de Ausubel. Além disso, pôde-se conhecer alguns tipos de tarefas em que os mapas conceituais podem ser utilizados, os passos para sua construção e os elementos que compõem sua estrutura, informações necessárias para se produzir bem um mapeamento de conceitos.

Outro ponto importante é a aprendizagem de manuseio do Cmap Tools em que vimos alguns passos para a construção de mapas conceituais digitais, os quais, feitos no aplicativo, podem apresentar uma estruturação dinâmica, personalizada e incrementada. Além das informações teóricas sobre o programa, constam também as informações práticas voltadas para os conhecimentos mais básicos de como se constrói um mapa de conceitos, mas também para funções interativas como a busca de outros Cmaps sobre o mesmo assunto, por exemplo e o conhecimento maior que pode ser adquirido através da opção de ajuda.

Em relação às vantagens do uso do Cmap Tools em sala de aula, sem dúvidas, é possível afirmar que o software pode auxiliar bastante o professor na explanação de conteúdos em sala de aula e, como consequência, proporcionar aos discentes um aprendizado significativo com base nos pressupostos de Ausubel. Qualquer estratégia que contribua para melhorias no ensino e, consequentemente, na aprendizagem deve ser pesquisada e explorada e Cmap Tools proporciona essa contribuição, de forma que é válido explorá-lo e descobrir suas inúmeras vantagens para o trabalho com a aprendizagem.

Enfim, esperamos que a proposta deste artigo possa ser aplicada a fim de novos olhares e novas contribuições surgirem para a ampliação das estratégias de ensino. Os recursos digitais estão imensamente presentes na nossa vida cotidiana e apostar neles no 
contexto escolar é uma boa ideia, levando-se em conta a necessidade de inovação e de melhorias no âmbito do trabalho em sala de aula.

\section{Referências}

BEZERRA, J. J. Uma análise das contribuições de mapas conceituais na reescrita e na retextualização de contos no $9^{\circ}$ ano do ensino fundamental. 2018. 137f. Dissertação (Mestrado) - PROFLETRAS - Mestrado Profissional em Letras, Universidade Federal de Campina Grande, Cajazeiras, 2018.

BEZERRA, J. J. Mapas conceituais: uma proposta para o ensino e para a avaliação da aprendizagem. In: I SEMANA NACIONAL DE LETRAS: linguagem e ensino homenagem a Luiz Antonio Marcuschi, 1. 2016, Cajazeiras-PB. QUEIROGA, Marcílio Garcia de. (Org.) Anais eletrônicos... Cajazeiras: 2017. p. 120-129. Disponível em: https://semanadeletrascfpufcg.wordpress.com/anais/. Acesso em: 17 dez. 2017.

COSTA, J. E; BRENNAND, E. G. G.; ALBUQUERQUE, M. E. B. C de. Mapa conceitual: ferramenta de estruturação de conhecimentos e saberes. In BRENNAND, E. G. G.; M. E. B. C. ALBUQUERQUE. Formação docente e tecnologias digitais. João Pessoa: Editora UFPB, 2011.

MARRIOTT, R. de C. V.; TORRES, P. L. Mapas conceituais: uma ferramenta para a construção de uma cartografia do conhecimento. [S. 1.]: (Coleção Agrinho), 2014.Disponível em <http://www.agrinho.com.br/site/wpcontent/uploads/2014/09/2_09_Mapas-conceituais.pdf>. Acesso em: 16 out. 2016.

MOREIRA, M. A.; BUCHWEITZ, B. Mapas conceituais: instrumentos didáticos, de avaliação e de análise de currículo. São Paulo: Editora Moraes, 1987.

MOREIRA, M. A. Mapas Conceituais e Aprendizagem Significativa. São Paulo: Centauro, 2010.

NOVAK, Joseph D.; CAÑAS, Alberto J. A teoria subjacente aos mapas conceituais e como elaborá-los e usá-los. Tradução de Luis Fernando Cerri (PPGE/UEPG), com revisão técnica de Fabiano Morais. Práxis Educativa, Ponta Grossa, v.5, n.1, p. 9-29, jan. -jun. 2010. Disponível em <http://www.periodicos.uepg.br>. Acesso em: $18 \mathrm{dez}$. 2016. 